\title{
Robust power control methods for wind turbines using DFIG-generator
}

\author{
Imane El Karaoui ${ }^{1}$, Mohammed Maaroufi ${ }^{2}$, Badre Bossoufi ${ }^{3}$ \\ ${ }^{1}$ Department of Electrical Engineering, Mohammadia School of Engineers (EMI), Mohammed V University, Morocco \\ ${ }^{2}$ LISTA Laboratory, Faculty of Sciences Dhar El Mahraz, Sidi Mohamed Ben Abdellah University, Fez, Morocco \\ ${ }^{3}$ Laboratory of Electrical Engineering and Maintenance, Higher School of Technology, EST-Oujda, University of \\ Mohammed I, Morocco.
}

\begin{abstract}
Article Info
Article history:

Received Jan 15, 2019

Revised Mar 1, 2019

Accepted Jun 1, 2019

Keywords:

DFIG

FOC

MPPT

Sliding mode control,

Matlab/Simulink

Wind turbine

ABSTRACT

The purpose of this work is to present the advantages of the power control (active and reactive) of a wind energy system in order to improve the quality of the energy produced to the grid by presenting two control strategies applied to the conversion system of wind energy equipped with an asynchronous generator with dual power supply. Both techniques are studied and developed and consist of a field control (FOC) and a sliding mode control. They find their strongest justifications for the problem of using a nonlinear control law that is robust to the uncertainties of the model. The goal is to apply these two commands to independently control the active and reactive powers generated by the decoupled asynchronous machine by flow orientation. Thus, a study of these commands will be detailed and validated in the Matlab / Simulink environment with the simultaneous use of the "Pitch Control" and "Maximum Power Point Tracking (MPPT)" techniques. The results of numerical simulations obtained show the increasing interest of the two controls in the electrical systems. They also attest that the quality of the active and reactive powers and voltages of the wind system is considerably improved.
\end{abstract}

Copyright $(\mathbb{C} 2019$ Institute of Advanced Engineering and Science. All rights reserved.

\section{Corresponding Author:}

Imane El Karaoui

Department of Electrical Engineering, Mohammadia School of Engineers (EMI),

Mohammed V University, Rabat, MOROCCO

Email: elkaraoui.imane@gmail.com

\section{INTRODUCTION}

Today, Doubly Fed Induction Generator (DFIG) is widely used for power generation in wind farms because of its high efficiency, energy quality and the ability to control power supplied to the network [1-3]. However, DFIG-based wind turbines have a number of disadvantages such as their sensitivity to load disturbances, turbine's rotational speed variation, and internal and external parameters of the system.

Similarly, the system is multi-variable, dynamic, highly coupled and non-linear, making control very difficult [4]. On the other hand, the need for development of wind farms for the use of renewable sources, pushed the evolution of research in the field to improve the efficiency of the electromechanical conversion and the quality of the electrical energy supplied by different controls. [5]. The main idea of this approach is to analyze the stability of the nonlinear system without solving the differential equations of this system. It is a very powerful tool to test and find sufficient conditions for the stability of different dynamic systems. The study presented in this paper aims to optimize the energy performance of a wind turbine in order to maximize the wind energy captured while reducing structural problems cited previously and improve control performance by reducing time of calculation. This optimization is capable to minimize the costs of electricity production.

Journal homepage: http://iaescore.com/journals/index.php/IJPEDS 
In this paper, we will start by exposing a wind turbine modeling. Then, a study of the operating point tracking technique and maximum power will be presented. Subsequently, we present a DFIG model in the "dq" frame and the general principle of controlling both power converters which is based on the control strategy (FOC, and Sliding Mode).

In this work, we develop two control strategies entitled: Field Oriented Control (FOC), and Sliding Mode Control. A study of these commands is detailed and developed in Matlab / Simulink environement. Finally, the results are analyzed to compare the effectiveness of the controlled system of the two control strategy.

\section{WIND TURBINE MODELLING}

\subsection{Energy conversion chain} in Figure 1.

The overall diagram of a wind energy conversion chain connected to the power grid is depicted

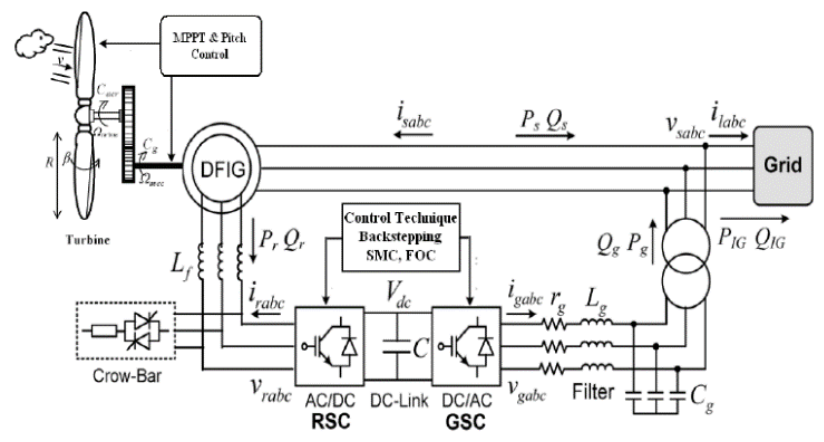

Figure 1. Diagram of an energy conversion chain

\subsection{Modelling of the wind turbine Power}

In this part, we define the mathematical model used in modeling the wind system. The expression of the mechanical power captured by the wind turbine and transmitted to the rotor (Rotor) is expressed by [3]:

$$
\begin{aligned}
& P_{\text {Rotor }}=P_{\text {wind }} \cdot C_{p}(\lambda, \beta) \\
& P_{\text {wind }}=\frac{1}{2} \rho S v^{3} \\
& P_{\text {Rotor }}=\frac{1}{2} \rho S . C_{p}(\lambda, \beta) v^{3}
\end{aligned}
$$

With $C p(\lambda, \beta)$ is the power coefficient, $v$ is the wind speed $(\mathrm{m} / \mathrm{s}), \rho$ is the air density and $S$ is the swept area $\left(m^{2}\right)$

Betz proved that the maximum extractable power for a given wind speed by ideal turbine and conditions is $C_{\text {pmax }}(\lambda, \beta)=0.593$, this limit is known as the Betz limit. For the DFIG, it is possible to model the power coefficient $\left(C_{p}(\lambda, \beta)\right)$ with a single equation that depends on the tip speed ratio $(\lambda)$ and the pitch angle $(\beta)$ of the blades. This can be written as:

$$
C_{p}(\lambda, \beta)=c_{1} \cdot\left(c_{2} \cdot \frac{1}{A}-c_{3} \cdot \beta-c_{4}\right) \cdot e^{-c_{5} \frac{1}{A}}+c_{6} \cdot \lambda
$$

$$
\begin{aligned}
& \text { With } \\
& c_{1}=1.5872 \\
& c_{2}=116 \\
& c_{3}=0.4 \\
& c_{4}=5 \\
& c_{5}=21 \\
& c_{6}=0.0085 \\
& \frac{1}{A}=\frac{1}{\lambda+0.08 \cdot \beta}-\frac{0.035}{1+\beta^{3}}
\end{aligned}
$$




$$
\lambda=\frac{\Omega_{t} \cdot R}{V}
$$

The wind turbine is characterized by the curves of the coefficient power, which corresponds to the aerodynamic torque $\left(T_{\text {rotor }}\right)$, shown in following equation.

$$
T_{\text {rotor }}=\frac{P_{\text {rotor }}}{\Omega_{t}}=\frac{1}{2} \rho S \cdot C_{p}(\lambda, \beta) v^{3} \cdot \frac{1}{\Omega_{t}}
$$

It is necessary to connect the wind turbine and the DFIG to the Gearbox in order to adapt the speed of the turbine to that of the generator. It is modeled by the two following equations:

$$
\begin{aligned}
& \Omega=G . \Omega_{t} \\
& T_{\text {rotor }}=G . T_{m}
\end{aligned}
$$

The evolution of the generator speed $(\Omega)$ depends on the fundamental equation of the dynamic that characterizes the mechanical behavior of the turbine and generator from the total mechanical torque applied to the rotor. It is given by the following formula (Figure 2):

$$
J \frac{d \Omega}{d t}=T_{m}-T_{e m}-f . \Omega
$$

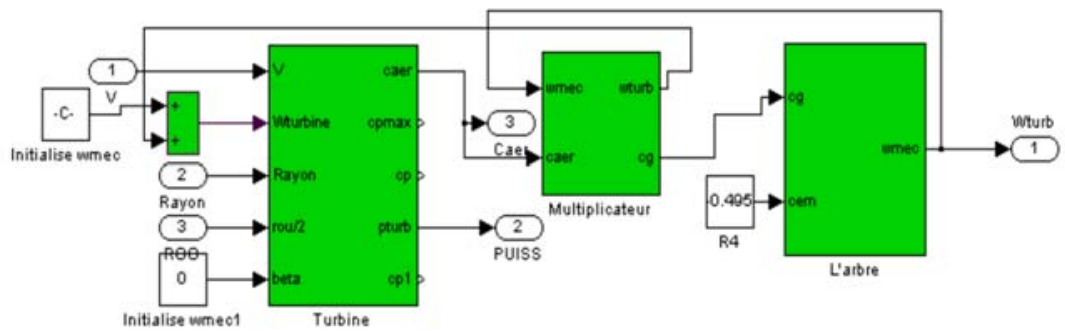

Figure 2. Wind-turbine model

\subsection{Mechanical regulation of the power of a wind turbine-pitch control}

A wind turbine is sized to develop on its shaft a power called Pn nominal power obtained from a wind speed vn, called nominal speed. When the wind speed is greater than vn, the wind turbine must modify its parameters in order to avoid mechanical destruction, so that its rotation speed remains practically constant. [6-10].

Beside the nominal speed $v_{n}$, we also specify:

a. The starting speed $v_{d}$, from which the wind turbine starts to supply energy

b. The maximum wind speed $v_{m}$, for which the turbine no longer converts wind energy, for reasons of operational safety. wind speed:

The speeds $v_{n}, v_{d}$ and $v_{m}$ define four zones on the diagram of the useful power as a function of the

a. Zone I, where $P=0$, the turbine does not work.

b. Zone II, in which the power supplied on the tree depends on the wind speed $v$.

c. Zone III, where the speed of rotation is kept constant and the power $P$ supplied remains equal to $P n$.

d. Zone IV, in which the operating safety system stops the transfer of energy [6-10].

So, the control of the wedge angle is in zone III in order to maintain, using the orientation of the blades of the turbine, the power extracted at a value called nominal value

We present below the influence of the variation of the angle of calage on the value of the power coefficient, which represents the energy efficiency of the turbine (Figure 3 and Figure 4) 


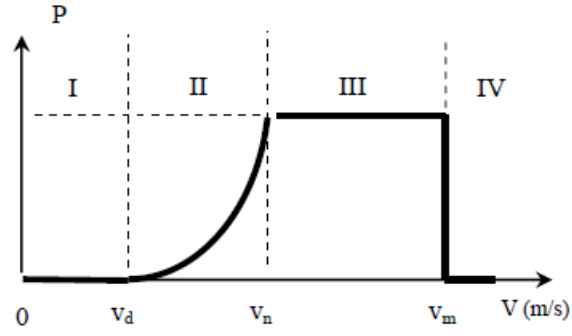

Figure 3. Diagramme de la puissance utile sur l'arbre en fonction de la vitesse du vent

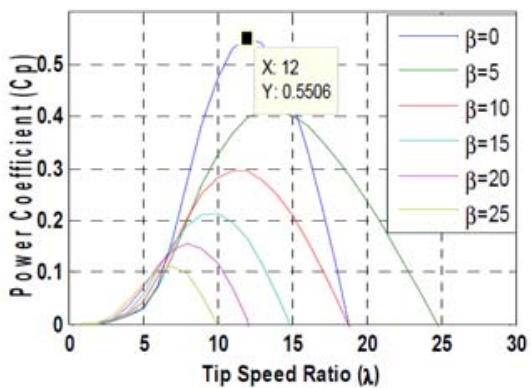

Figure 4. Influence of the angle $\beta$ on the power coefficient

It can be seen that as the wedge angle increases, the efficiency of the turbine decreases.

The control of the wedge angle $\beta$ for the orientation of the blades of the turbine can be achieved at a single loop control or two (Figure 5 and 6):

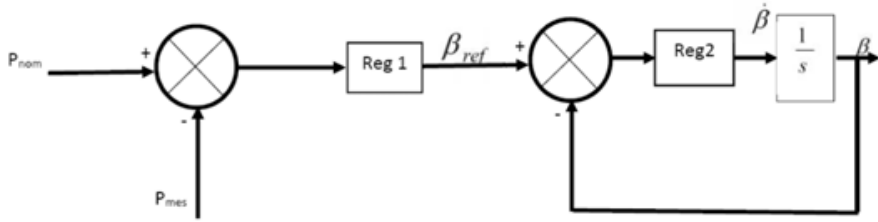

Figure.5. Control of the angle $\beta$ using a loop control



Figure.6. Control of the angle $\beta$ using double-loop control

The control performed by a single loop control is used to control the nominal power. The output of the regulator of the nominal power then corresponds to the reference value of the angle $\beta$, and it is transmitted to the system of orientation of the blades by an open-loop control.

When the control is carried out with double-loop control, the first corresponds to the control of the nominal power, and the second to the control of the calibration angle.

The second control mode is more complex to implement in terms of the synthesis of regulators, and it is more expensive since it requires the use of two regulators for its control.

\subsection{Principle of power control}

There are two principles of aerodynamic control to limit the power extracted from the turbine to the rated power of the generator: [2-6]

a. "pitch" or "variable pitch" system that adjusts the lift of the blades to the wind speed to maintain a substantially constant power in the speed zone III

b. "stall" or "aerodynamic stall" system, the most robust because it is the shape of the blades that leads to a loss of lift beyond a certain wind speed, but the power curve drops faster: it is therefore a passive solution.

The first principle is associated a blade orientation mechanism, allowing the variation of the wedging angle during the operation of the wind turbine to allow it to adapt to different wind conditions. The interest of this control appears by observing the characteristics of Figure 7 that present the power of the turbine as a function of the speed of rotation for different wind speeds.

Int J Pow Elec \& Dri Syst Vol. 10, No. 4, Dec 2019 : 2101 - 2117 


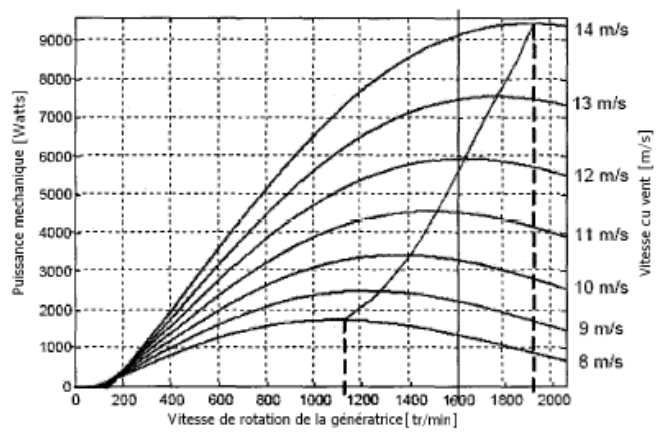

Figure 7. Power of a turbine according to its speed of rotation, Set in wind speed.

\subsection{MPPT strategy}

We have seen above that the extraction of wind power depends on the value of the power coefficient. The figure, below, represents the power according to the rotational speed of a given turbine (Figure 8):

It can be seen that, for each value of wind speed $\mathrm{V}$, the characteristics power - rotational speed graph goes through a maximum corresponding to a maximum power reached by an optimal rotational speed. However, the maximum power is obtained for a maximum power coefficient (Figure 9):

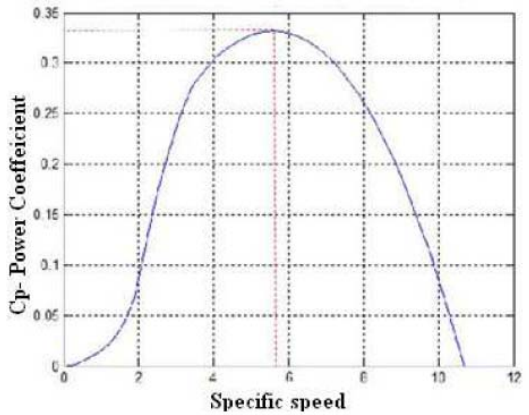

Figure 8. MPPT-Power of wind turbine

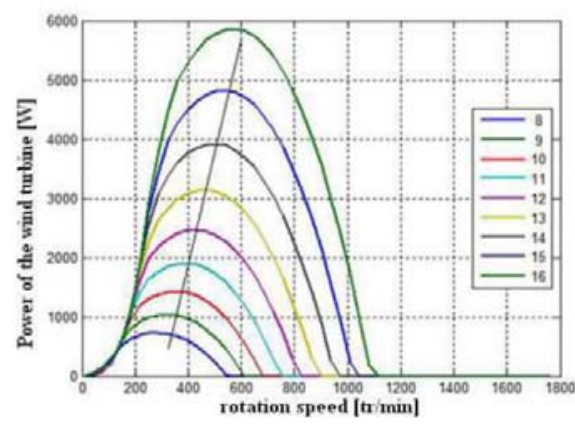

Figure 9. MPPT-Power coefficient $\mathrm{cp}$

This maximum value of the power coefficient corresponds to an optimal specific speed $\lambda o p t$. This specific speed is obtained for an optimal rotational speed:

$$
\Omega_{o p t}=\frac{\lambda_{o p t} \cdot V}{R}
$$

This optimal value of the rotational speed is sent as a reference for the speed control of electrical machines.

The speed control of the electrical machines can be achieved either in scalar control or in vector control (also called Field Oriented Control). The scalar command is used for the steady-state control while the vector control is used in transient mode. As part of this thesis, we opted for vector control, since the models used are developed under transient conditions. The control is more precise and faster, and moreover it allows a control of the magnitudes in amplitude and phase.

Also, the control of the static converter in the machine side makes possible to control the torque of the generator in order to obtain the desired rotational speed to extract the maximum power. This consists in controlling the electrical machine by a general cascade structure using nested loops.

Torque and flux, therefore, will be controlled by very fast internal current loops. These commands are carried out in a rotating frame (vector control with flux oriented). The torque setpoint is obtained from a 
slower external speed control loop. As for the speed reference, it is calculated from a MPPT strategy as presented above.

\section{MODELLING OF THE DFIG}

The generator chosen for the conversion of wind kinetic energy is the double-feed asynchronous generator [11-12].

The modeling of the DFIG is described in the Park reference system. The following equation system describes the global modeling of the generator that connects the voltages to the currents, the speed, the flow of the machine, and also the mechanical equation.

\subsection{Electrical equations}

Stator and rotor voltage

$$
\begin{aligned}
& V_{d s}=R_{s} I_{d s}+\frac{d \varphi_{d s}}{d t}-\theta_{s} \varphi_{q s} \\
& V_{q s}=R_{s} I_{q s}+\frac{d \varphi_{q s}}{d t}-\theta_{s} \varphi_{d s} \\
& V_{d r}=R_{r} I_{d r}+\frac{d \varphi_{d r}}{d t}-\theta_{r} \varphi_{q r} \\
& V_{q r}=R_{r} I_{q r}+\frac{d \varphi_{q r}}{d t}-\theta_{r} \varphi_{d r}
\end{aligned}
$$

Stator and rotor currents

$$
\begin{aligned}
I_{d s} & =\frac{1}{\sigma \cdot L_{s}} \cdot \varphi_{d s}-\frac{M}{\sigma \cdot L_{r}} \cdot \varphi_{d r} \\
I_{q s} & =\frac{1}{\sigma \cdot L_{s}} \cdot \varphi_{q s}-\frac{M}{\sigma \cdot L_{s} \cdot L_{r}} \cdot \varphi_{q r} \\
I_{d r} & =\frac{1}{\sigma \cdot L_{r}} \cdot \varphi_{d r}-\frac{M}{\sigma \cdot L_{r}} \cdot \varphi_{d s} \\
I_{q r} & =\frac{1}{\sigma \cdot L_{r}} \cdot \varphi_{q r}-\frac{M}{\sigma \cdot L_{s} \cdot L_{r}} \cdot \varphi_{q s}
\end{aligned}
$$

Stators and rotor flux

$$
\begin{aligned}
& \varphi_{d s}=L_{s} I_{d s}+M I_{d r} \\
& \varphi_{q s}=L_{s} I_{q s}+M I_{q r} \\
& \varphi_{d r}=L_{r} I_{d r}+M I_{d s} \\
& \varphi_{q r}=L_{r} I_{q r}+M I_{q s} \\
& T_{e m}=T_{r}+f \Omega+J \frac{d \Omega}{d t}
\end{aligned}
$$

Stator and rotor powers

The control of the DFIG must allow an independent control of the active and reactive powers by the rotor voltages generated by an inverter.

In the two-phase reference system, the active and reactive stator and rotor powers of an asynchronous generator are written:

$$
\begin{aligned}
& P_{s}=\frac{3}{2}\left(V_{d s} \cdot I_{d s}+V_{q s} \cdot I_{q s}\right) \\
& Q_{s}=\frac{3}{2}\left(V_{q s} \cdot I_{d s}+V_{d s} \cdot I_{q s}\right) \\
& P_{r}=\frac{3}{2}\left(V_{d r} \cdot I_{d r}+V_{q r} \cdot I_{q r}\right) \\
& Q_{r}=\frac{3}{2}\left(V_{q r} \cdot I_{d r}+V_{d r} \cdot I_{q r}\right)
\end{aligned}
$$

\subsection{Mechanical equations}

The electromechanical torque can be determined by the following equations (Figure 10): 


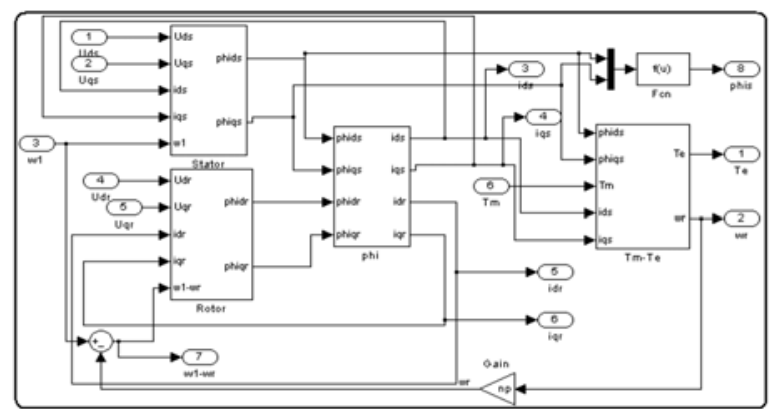

Figure 10. DFIG model

$$
T_{e m}=p\left(I_{d s} . \varphi_{q s}-I_{q s} . \varphi_{d s}\right)
$$

For obvious reasons of simplification, a d-q reference linked to the stator rotating field and a stator flux aligned with the $\mathrm{d}$ axis have been adopted [11]. In addition, the stator resistance can be neglected since this is a realistic assumption for generators used in wind power. On the basis of these considerations, the torque becomes

$$
T_{e m}=p \frac{M}{L_{s}}\left(\varphi_{d s} \cdot I_{q r}-\varphi_{q s} I_{d r}\right)
$$

\section{FIELD ORIENTED POWER CONTROL}

\subsection{Principe of power control}

The principle of stator flux orientation control is based on [13]: $\varphi_{d s}=\varphi_{s}$ and $\varphi_{q s}=0$.

For large wind turbines, the stator resistors are negligible, and also the flux becomes constant. For this, the flux has an expression:

$\varphi_{q s}=0=L_{s} I_{q s}+M \cdot I_{q r}$

$\varphi_{q s}=L_{s} I_{d s}+M \cdot I_{d r}$

From stator and rotor equations, we obtain:

$$
\begin{aligned}
I_{q s} & =\frac{M}{L_{s}} I_{q r} \\
I_{d s} & =\frac{1}{L_{s}}\left(\varphi_{s}-M \cdot I_{d r}\right)
\end{aligned}
$$

The expression of the electromagnetic torque [14]:

$$
T_{e m}=p \varphi_{s} . I_{q s}=-p \frac{M}{L_{s}} \varphi_{s} I_{q r}
$$

Based on the assumptions:

$$
\begin{aligned}
& V_{d s}=0 \\
& V_{d s}=V_{s}=\omega_{s} \cdot \varphi_{s} \\
& \varphi_{s}=\frac{V_{s}}{\omega_{s}}
\end{aligned}
$$

The active power $P_{S}$ and the reactive power $Q_{s}$ of the wind system can be written [14]

$P_{s}=V_{d s} \cdot I_{d s}+V_{q s} \cdot I_{q s}$

$Q_{s}=V_{q s} . I_{d s}-V_{d s} . I_{q s}$

From the previous equation, we obtain [14]:

$$
\begin{aligned}
& P_{s}=V_{s} \cdot I_{q s}=V_{s} \cdot \frac{M}{L_{s}} I_{q r} \\
& Q_{s}=V_{s} \cdot I_{d s}=\frac{V_{s}^{2}}{\omega_{s} L_{s}}-V_{s} \cdot \frac{M}{L_{s}} I_{d r}
\end{aligned}
$$


The rotor flux is given by:

$$
\begin{aligned}
\varphi_{d r} & =\left(L_{r}-\frac{M^{2}}{L_{s}}\right) \cdot I_{d r}+M \frac{V_{s}}{\omega_{s} L_{s}} \\
\varphi_{q r} & =\left(L_{r}-\frac{M^{2}}{L_{s}}\right) \cdot I_{q r}
\end{aligned}
$$

Subsequently, the control vectors $V_{d r}$ and $V_{q r}$ can be determined by the equations:

$$
\begin{aligned}
& V_{d r}=\left[\left(R_{r}+S \cdot\left(L_{r}-\frac{M^{2}}{L_{s}}\right)\right] \cdot I_{d r}-\omega_{s} \cdot g \cdot\left(L_{r}-\frac{M^{2}}{L_{s}}\right) \cdot I_{q r}\right. \\
& V_{q r}=\left[\left(R_{r}+S \cdot\left(L_{r}-\frac{M^{2}}{L_{s}}\right)\right] \cdot I_{q r}-\omega_{s} \cdot g \cdot\left(L_{r}-\frac{M^{2}}{L_{s}}\right) \cdot I_{d r}+g \cdot \frac{M}{L_{s}} \cdot V_{s}\right.
\end{aligned}
$$

The following figure shows the diagram block using Simulink that models the equations defined previously:

The Figure 6 shows the modeling of DFIG equations using first-order transfer functions for voltages. The vector control will be easily implemented later, considering that the slip value $\mathrm{g}$ is negligible and the influence of the coupling is weak.

\subsection{FOC technique}

In this work, we use two types of vector control. The first is based on controlling the rotor voltage of the DFIG to control the power of the system (Figure 11).

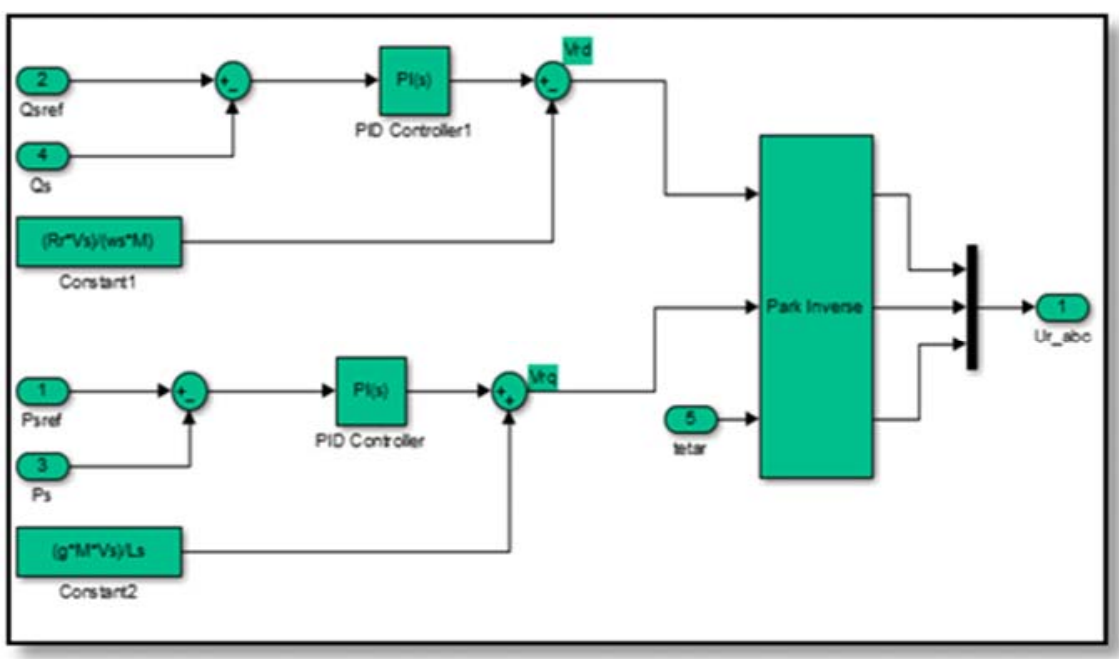

Figure 11. Direct vector control

The second type (indirect control) is based on controlling the rotor current to control the power. The control vector is generated from Equations 19 and 21 (Figure 12).

\subsection{Simulation results}

In this part, we present the simulation results of the proposed model for direct and indirect control of flux (FOC) (Figure 12). 




Figure 12: FOC control
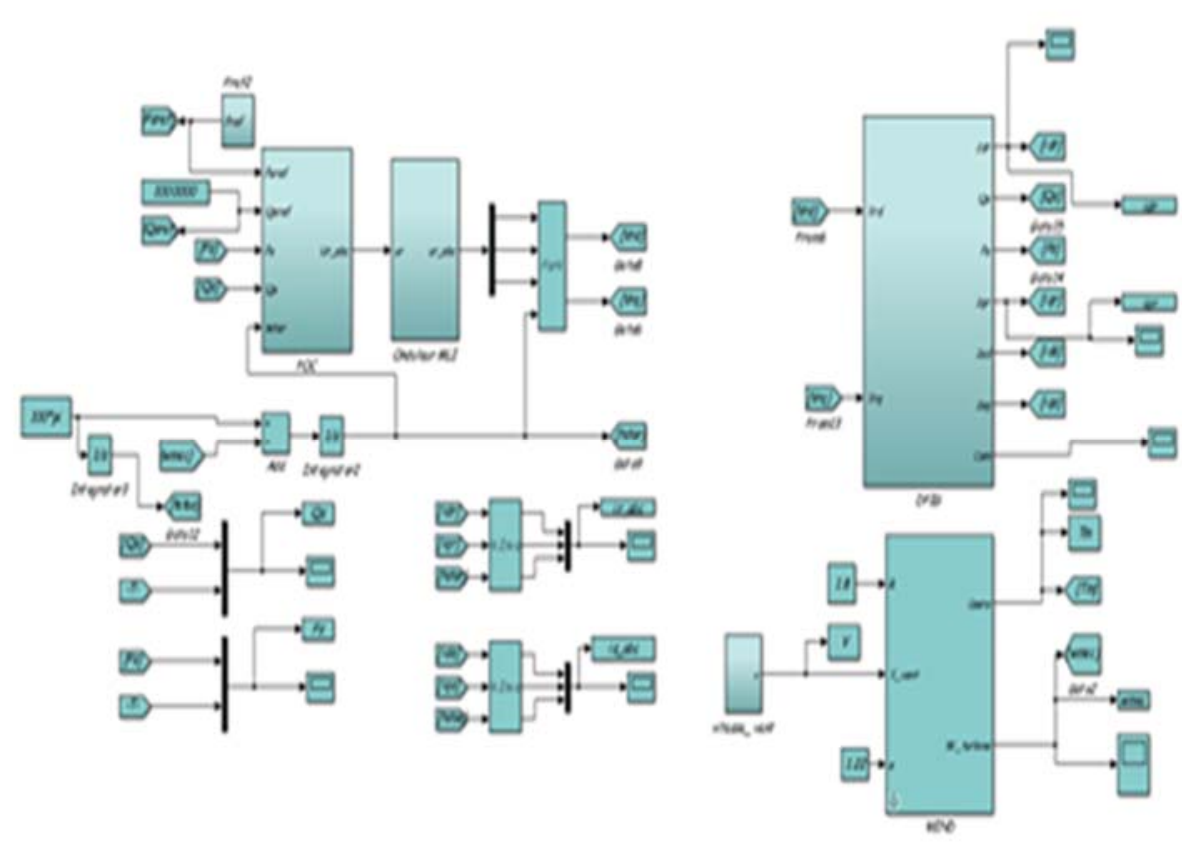

Figure 13. Direct vector control of a wind system based on DFIG

The Figure 14 present the simulation results for the proposed control models: 

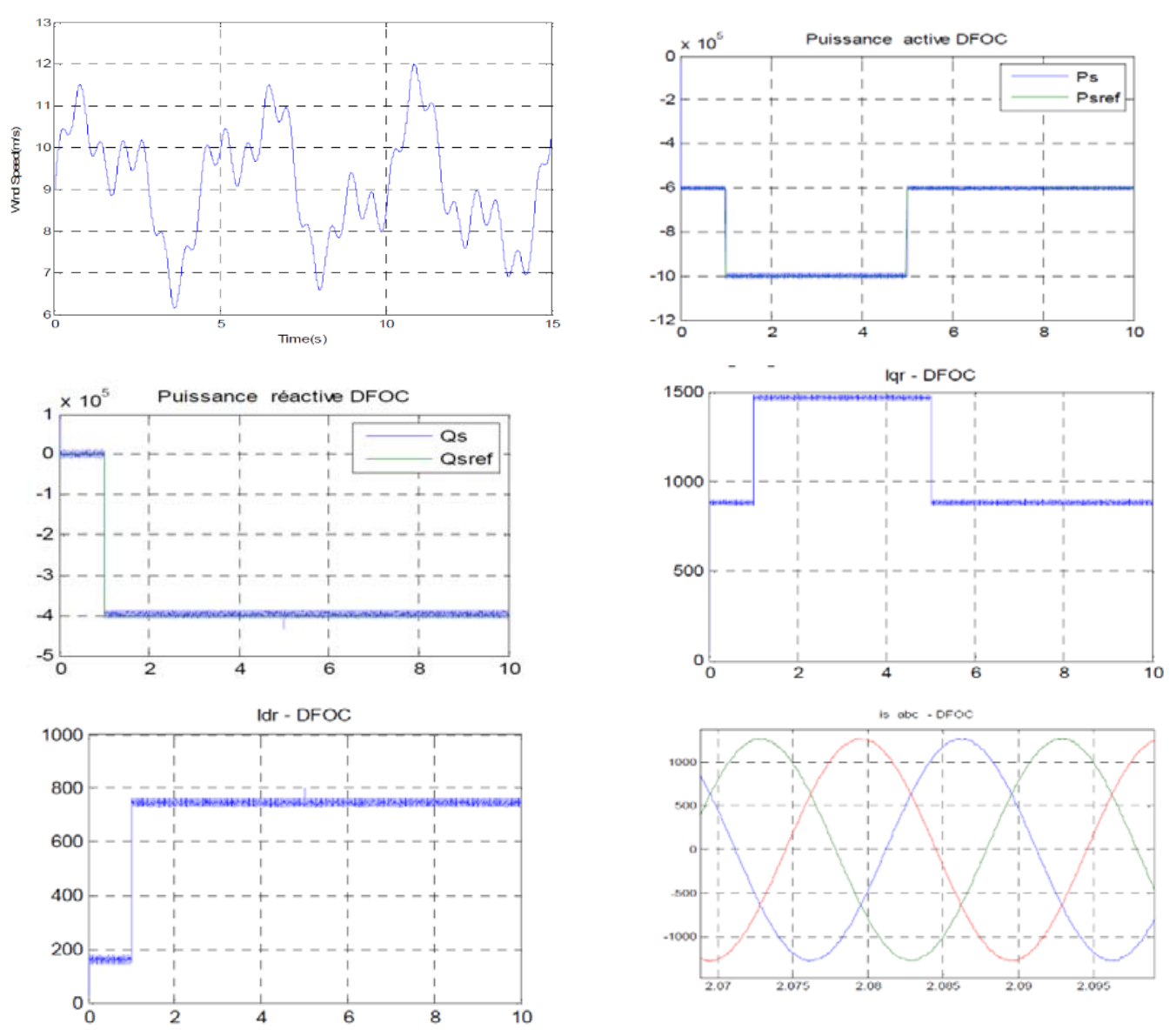

Figure 14. Results of simulation of a wind system based on the DFIG variable speed

\section{SLIDING MODE POWER CONTROL}

\subsection{Sliding mode power control strategy}

The principle of this technique consists in bringing the states trajectory of a system towards the sliding surface and to switchs it by means of appropriate switching logic around it to thesequilibrium point (Figure 15); hence, the phenomenon of slip [15-16].

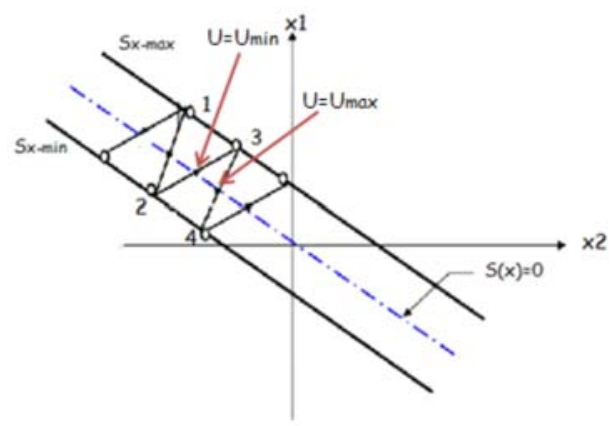

Figure 15. The trajectory in the phase plane 
The design of the sliding mode control algorithm is carried out mainly in three complementary steps defined by [15-16]:

\subsubsection{Sliding surfaces:}

Considering the following non-linear system:

$\dot{x}=f(x, t)+B(x, t) \cdot u(x, t)$

Where:

$x \in R^{n}$ : Statut Vector, $f(x, t) \epsilon R^{n}, B(x, t) \epsilon R^{n * m}, u \in R^{m}$ : Statut Vector

In order to ensure the convergence of a state variable to its reference value, it is necessary to choose a sliding surface which is a scalar function,so that ,the variable to be adjusted slides on the latter.

J. SLOTINE proposes a form of general equation [15-17] given by:

$$
S(x)=\left(\frac{d}{d t}+\delta\right)^{n-1} \cdot e(x)
$$

Where:

$\delta$ : Positive gain ; $(x)=x_{d}-x$ : Deviation of the variable to be regulated; $n$ : is a relative degree which represents the number of times that the surface must be derived to make the command appear .

The objective of the command is to keep the surface at zero. The latter is a linear differential equation whose unique solution is $e(x)=0$.

\subsubsection{Conditions of existence and convergence:}

In order to ensure the convergence mode, LYAPUNOV proposes a function $V(x)$ which guarantees the stability of the nonlinear system and the attraction of the variable to be controlled to its reference value, the latter is defined as follows:

$$
V(x)=\frac{1}{2} \cdot S(x)^{2}>0
$$

For decreasing the function $(x)$, it suffices to ensure that its derivative $V \dot{(x)}=S(x) . \dot{S(x)}<0$. The idea is to choose a scalar function $S(x)$ to guarantee the attraction of the variable to be controlled to its reference value, and to design a command " $U$ ", so that the square of the surface corresponds to a function of LYAPUNOV [16].

\subsubsection{Determination of the control law}

Once the sliding surface and the criterion of convergence have been chosen, it remains to determine the control necessary to attract the state trajectory towards the surface and then towards its equilibrium point while maintaining the conditions of existence of the sliding mode.

The command $(u)$ is a variable structure command given by [18]

$$
u= \begin{cases}u^{+}(x), & s(x, t)>0 \\ u^{-}(x), & s(x, t)<0\end{cases}
$$

Where: $u^{+}$and $u^{-}$are continuous functions, with $u^{-} \neq u^{+}$

This control $(u)$ of discontinuous nature will force the trajectories of the system to reach the sliding surface and to remain there in the vicinity of the latter despite the presence of the disturbances.

The system trajectories on the surface $\mathrm{S}$ are not defined since the command $(u)$ is not defined for $S=0$, to do this, FILLIPOV [19] and UTKIN [20] propose a method called " The Equivalent Command » $[16,21]$ (Figure 16). The addition of this command pre-positions the system in a desired stable state [22] and in addition reduces the CHATTERING phenomenon. 


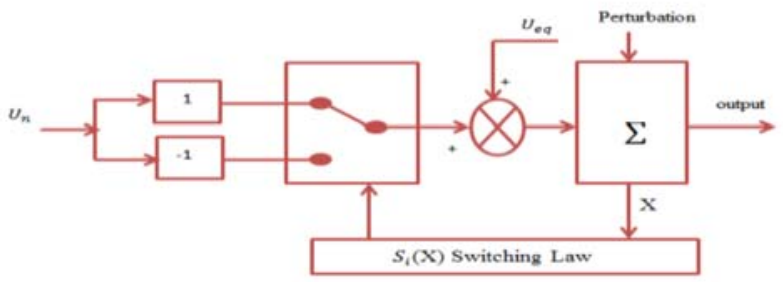

Figure 16. The equivalent command

This structure consists of two parts [16], one concerning the exact linearization $\left(U_{e q}\right)$ and the other the stability $\left(U_{n}\right)$.

$U=U_{e q}+U_{n}$

$\left(U_{e q}\right)$ is used to keep the variable to be controlled on the sliding surface $(x)=0$. It is deduced, considering that the derivative of the surface is zero $\dot{S(x)}=0$.

Considering the state system (17), we sought to determine the analog expression of the control $U$.

The derivative of the surface $S(x)$ is given by the following equation:

$$
S(x)=\frac{\partial S}{\partial t} \cdot f(x)+\frac{\partial S}{\partial t} \cdot B(x) \cdot U_{e q}+\frac{\partial S}{\partial t} \cdot B(x) \cdot U_{n}
$$

In the sliding and permanent regime, the sliding surface is zero and its derivative as well as the discontinuous part are also null, so the expression of the equivalent command becomes as follows:

$U_{e q}=-\frac{\partial S}{\partial t} \cdot f(x) \cdot\left(\frac{\partial S}{\partial t} \cdot B(x)\right)^{-1}$

It is necessary that $\frac{\partial S}{\partial t} . B(x) \neq 0$, so that the equivalent command can take a finite value.

By replacing $U_{e q}$ with its expression in $\dot{(x)}$, we obtain:

$S(x)=\frac{\partial S}{\partial t} \cdot B(x) \cdot U_{n}$

In order to satisfy the condition of attractiveness $S(x) . S(x)^{*}<0$, the sign $U_{n}$ of must be opposed to that of $\frac{\partial S}{\partial t} \cdot B(x) \cdot S(x)$.

The discontinuous control $\left(U_{n}\right)$ forces the dynamics to converge towards the surface and ensures the insensitivity of the system with respect to uncertainties and perturbations.

Several forms are proposed in the literature [21,23], the simplest one is given by the following expression $U_{n}=K \cdot \operatorname{sign}(S(x))$

Where: $K$ is a positive constant and (sign) the classical sign function.

But the main disadvantage of the relay type control is the phenomenon well known by "CHATTERING". In steady state, the latter appears as a high frequency oscillation around the equilibrium point (Figure 17), because of the very discontinuous nature of the sign function.

To remedy this problem, several investigations have been made. One of the solutions envisaged consists in introducing a stop band around the switching surface. To do this, it suffices to replace the function (sign) with the saturation function (Sat), whose discontinuities in the vicinity of zero are less brutal.

This saturation function can be expressed by the following equation [15-16].

$$
\operatorname{sat}(\varphi)\left\{\begin{array}{c}
1 \text { if } \varphi>\varepsilon \\
-1 \text { if } \varphi<\varepsilon \\
\frac{\varphi}{\varepsilon} \text { if }|\varphi| \leq \varepsilon
\end{array}\right.
$$




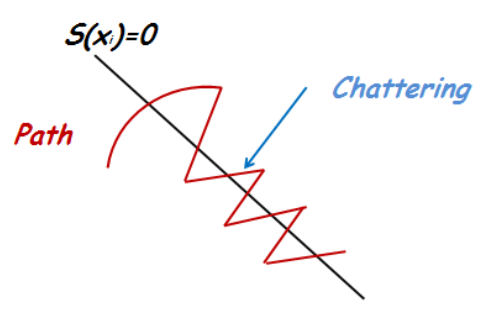

Figure 17. Phenomenon of "CHATTERING"

\subsubsection{Application of the sliding mode command to the DFIG.}

After presenting the theory of Sliding Mode Control, we will analyze in this part the application of the sliding mode control to the DFIG.

According to the Field Oriented Control principle, the quadrature component of the stator field is forced to zero and the direct component is equal to the total stator field.

The preceding equations become as follows:

$$
\begin{aligned}
& v_{s d}=0 \\
& v_{s q}=v_{s}=\omega_{s} \cdot \emptyset_{s} \\
& v_{r d}=R_{r} \cdot I_{r d}+\frac{d \emptyset_{r d}}{d t}+\omega_{r} \cdot \emptyset_{r q} \\
& v_{r q}=R_{r} \cdot I_{r q}+\frac{d \emptyset_{r q}}{d t}+\omega_{r} \cdot \emptyset_{r d} \\
& P_{s}=-V_{s} \cdot \frac{M}{L_{s}} \cdot I_{r q} \\
& Q_{s}=\frac{V_{s}^{2}}{\omega_{s} \cdot L_{s}}-V_{s} \cdot \frac{M}{L_{s}} \cdot I_{r d} \\
& \dot{I}_{r d}=\frac{v_{r d}}{L_{r} \cdot \sigma}-\frac{R_{r}}{L_{r} \cdot \sigma} \cdot I_{r d}+\omega_{r} \cdot I_{r q} \\
& \dot{I}_{r q}=\frac{v_{r q}}{L_{r} \cdot \sigma}-\frac{R_{r}}{L_{r} \cdot \sigma} \cdot I_{r q}-\omega_{r} \cdot \frac{M \cdot V_{s}}{L_{s} \cdot L_{r} \cdot \sigma \cdot \omega_{s}}
\end{aligned}
$$

\subsection{Active power control surface}

The sliding surface proposed by J.SLOTINE is given by the following equation:

$$
S(x)=\left(\frac{d}{d t}+\delta\right)^{n-1} e(x)
$$
as follows:

To control the active power, we take $n=1$, the expression of the active power control surface is

$$
S\left(P_{s}\right)=e\left(P_{s}\right)=P_{\text {sref }}-P_{S}
$$

Its derivative is given by equation (32):

$S\left(\dot{P}_{S}\right)=P_{\text {sref }}-\dot{P}_{S}$

We replace $\dot{P}_{s}$ by its expression as well as $I_{r q}$ obtaining us:

$S\left(\dot{P}_{S}\right)=P_{\text {sref }}+V_{s} \cdot \frac{M}{L_{s}} \cdot\left(\frac{v_{r q}}{L_{r} \cdot \sigma}-\frac{R_{r}}{L_{r} \cdot \sigma} \cdot I_{r q}-\omega_{r} \cdot \frac{M \cdot V_{s}}{L_{s} \cdot L_{r} \cdot \sigma \cdot \omega_{s}}\right)$

By replacing the expression of with, the command clearly appears in the following equation:

$S\left(\dot{P}_{s}\right)=P_{\text {sref }}+V_{s} \cdot \frac{M}{L_{s}} \cdot\left(\frac{V_{r q e q}+V_{r q n}}{L_{r} \cdot \sigma}-\frac{R_{r}}{L_{r} \cdot \sigma} \cdot I_{r q}-\omega_{r} \cdot \frac{M \cdot V_{s}}{L_{s} \cdot L_{r} \cdot \sigma \cdot \omega_{s}}\right)$ 
In sliding and permanent mode:

$$
\begin{aligned}
& S\left(P_{s}\right)=0 \\
& S\left(\dot{P}_{s}\right)=0 \\
& V_{r q n}=0 \\
& V_{r q e q}=-L_{s} \cdot L_{r} \cdot \frac{\sigma}{M \cdot V_{s}} \cdot P_{\text {sref }}+\left(R_{r} \cdot I_{r q}+L_{r} \cdot \sigma \cdot I_{r d}+\omega_{r} \cdot M \cdot \frac{V_{s}}{L_{s} \cdot \omega_{s}}\right)
\end{aligned}
$$

The discontinuous control is given $V_{r q n}$ by:

$V_{\text {rqn }}=K_{s} \cdot \operatorname{sat}\left(S\left(P_{s}\right)\right.$

Where: $K_{s}$ : Positive gain

\subsection{Reactive power control surface}

We take the same surface as that of the active power:

$S\left(Q_{s}\right)=e\left(Q_{s}\right)=Q_{\text {sref }}-Q_{s}$

The derivative of the surface is:

$S\left(\dot{Q}_{s}\right)=Q_{\text {sref }}-\dot{Q}_{s}$

We replace $\dot{Q}_{s}$ by its expression as well as $I_{r d}$, we get:

$S\left(\dot{Q}_{s}\right)=Q_{\text {sref }}+V_{s} \cdot \frac{M}{L_{S}} \cdot\left(\frac{V_{r d}}{L_{r} \cdot \sigma}-\frac{R_{r}}{L_{r} \cdot \sigma} \cdot I_{r d}\right)$

By replacing the expression of $V_{r d}$ with $V_{r d} e q+V_{r d n}$ we obtain the following equation:

$S\left(\dot{Q}_{s}\right)=Q_{\text {sref }}+V_{s} \cdot \frac{M}{L_{s}} \cdot\left(\frac{V_{r d e q}+V_{r d n}}{L_{r} \cdot \sigma}-\frac{R_{r}}{L_{r} \cdot \sigma} \cdot I_{r d}-\omega_{r} \cdot I_{r q}\right.$

In sliding and permanent mode:

$S\left(Q_{S}\right)=0$

$S\left(\dot{Q}_{S}\right)=0$

$V_{r d n}=0$

Hence, the formula of $V_{\text {rdeq }}$ becomes as follow:

$V_{r d e q}=-L_{s} \cdot L_{r} \cdot \frac{\sigma}{M \cdot V_{s}} \cdot Q_{s r e f}^{\cdot}+R_{r} \cdot I_{r d}-L_{r} \cdot \sigma \cdot I_{r q} \cdot \omega_{r}$

The discontinuous control $V_{r d n}$ is given by:

$$
V_{r d n}=K_{d} \cdot \operatorname{sat}\left(S\left(Q_{s}\right)\right.
$$

Where: $K_{d}$ : Positive gain

\subsection{Simulation results:}

In order to validate the robustness of the sliding control applied to a wind system based on the DFIG, the following figures show the results obtained from this application, where the following observations can be distinguished:

- The wind profile is given by (Figure 18).

- $\quad$ The aerodynamic power according to the MPPT has the same shape as that of the wind profile.

- $\quad$ The power coefficient $\mathrm{Cp}$ and the specific speed are kept around their optimal values 0.5505 and 8 respectively, which ensures maximum mechanical power 
- The rotation speed of the machineis less oscillating with a high reliability with respect to the input speed.

- The shape of the electromagnetic torque of the DFIGis negative with a shape different from that of the wind profile this is due to the dynamic torque of the inertia.

- $\quad$ Figure 18 shows the active stator power and its reference profile injected into the network, where a very good decoupling can be seen between the active and reactive power of the stator.

- The stator reactive power and its reference profile are shown in Figure 18, which gives a unit power factor factor $\cos \varphi(\varphi)=1$ because $(=0)$.Consequently, iron losses are minimized.

Figure 19 shows the stator currents that are purely sinusoidal with a constant frequency $50 \mathrm{~Hz}$ and consequently a minimization of harmonics and therefore a better injection into the grid.
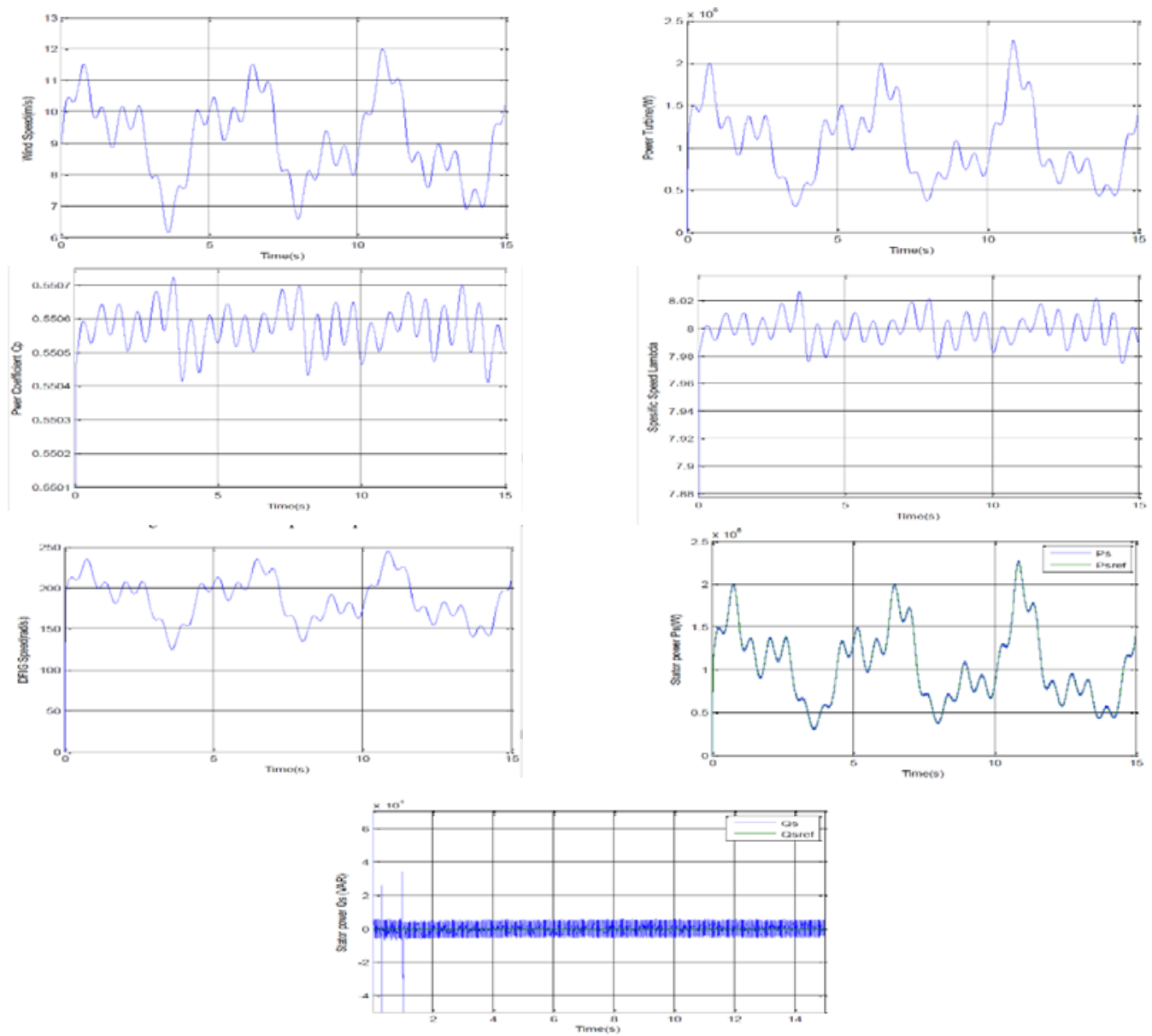

Figure 18. The reactive stator power(VAR)

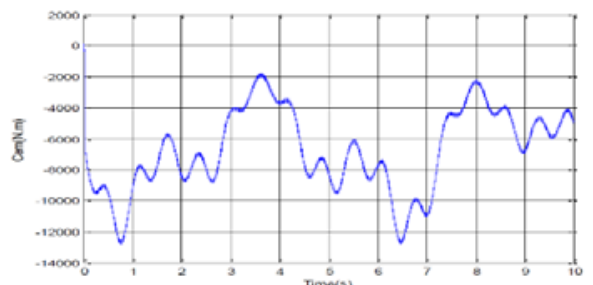

Figure19. Indirect field oriented control Result 
In this section, an analysis and interpretation of the results of the application of the sliding control to a wind system based on the DFIG will be presented as well as a comparison with a literature based on the same control [24].

The figures obtained present the different performances of the wind system, which show the robustness and good tracking of the references. The specific speed and the power coefficient vary in proportion to the wind speed, which shows the reliability of the system. The active and reactive power follows their references well, making the system more robust.

In paper [24], it is clear that the active and reactive power exhibit many oscillations, which implies less robustness. It can also be noted that the frequency of the stator current is different from that of the grid, which is one of the major problems of wind systems. By comparing these results with ours, we note that the wind system in our work is more reliable and robust, which makes it possible to make a better injection of power in the grid.

\section{COMPARISON BETWEEN DIFFERENT CONTROL STRATEGY: FOC AND SLIDING MODE}

6.1. Field oriented power control Advantage:

- The switching frequency is fixed;

- The harmonic content of currents is well defined;

- $\quad$ There is an application of the eight voltage vectors that can supply the voltage inverter;

- Good quality of regulation of the current in steady state; Disadvantages:

- The general structure of the control algorithm is complex to implement;

- Transient dynamics are slow;

- $\quad$ The parameters of the control algorithm depend on the parameters of the DFIG.

\subsection{Sliding mode power control} Advantage:

- $\quad$ The general structure of the control algorithm is simple to implement;

- Robustness ;

- $\quad$ The parameters of the control algorithm are independent of the parameters of the machine;

- Very good dynamics during transient regime; Disadvantages:

- The zero voltage vectors are not applied.

\section{Conclusion}

This work was devoted to modeling, simulation and analysis of a wind turbine operating at variable speed. The use of the two controls linear and non-linear (FOC, Sliding Mode) with the application of the MPPT and Pitch Control techniques, allows to improve the system performance and guarantee a good monitoring of the active and reactive powers.

The comparative study, between these two controls, shows that the Sliding Mode control offers several advantages such as the robustness and the linearization of the system than the other commands.

\section{REFERENCES}

[1] S. Pierre, C., Nichita, M. B., Camara, B. Dakyo, "Control strategy of a wind turbine simulation system designed fora hybrid wind-tidal real time emulator," 3rd Renewable Power Generation Conference (RPGTM), pp. 24-25, Naples, Italy, Sep 2014.

[2] B. Bossoufi, H. A., Aroussi, E. M., Ziani, M. Karim, A. Lagrioui, A.Derouich, M. Taoussi, "Robust adaptive Backstepping control approach of DFIG generators for wind turbines variable-speed," 2014 International Renewable and Sustainable Energy Conference (IRSEC), pp 791-797, 17-19 Oct 2014.

[3] B. Bossoufi, M. Karim, S. Ionita, A. Lagrioui, "Indirect sliding mode control of a permanent magnet synchronous machine: FPGA-based implementation with matlab \& simulink simulation," Journal of Theoretical and Applied Information Technology JATIT, pp. 32-42, vol. 29(1), Jul 2011.

[4] B. Bossoufi, M. Karim, A. Lagrioui, M. Taoussi, A. Derouich, "Observer backstepping control of dfig-generators for wind turbines variable-speed: FPGA-based implementation," Renewable Energy Journal (ELSIVER), vol. 81, pp. 903-917, Sep 2015

Int J Pow Elec \& Dri Syst Vol. 10, No. 4, Dec 2019 : 2101 - 2117 
[5] T. Ackermann and Soder, L., "An overview of wind energy-status 2002," Renewable and Sustainable Energy Reviews, vol. 6(1-2), pp. 67-127, 2002.

[6] B. Multon, "Etat de l'art des aérogénérateurs électriques," rapport ECRIN, May 2002.

[7] P. Enrici, "Introduction à la conversion d'énergie éolienne,"cours de DEA, Déc 2003.

[8] "Site Internet de l'Association Danoise de l'Industrieéolienne," Retrieved from http://www.windpower.org/fr/core.htm

[9] E. Bossanyi, "Wind energy handbook," New York: Wiley, 2000.

[10] Meny Ivan, "Modélisation et réalisation d'une chaîne de conversion éolienne petite puissance," Laboratoire d'électrotechnique de Montpellier (LEM).

[11] A. Tapia., "Modeling and control of a wind turbine driven doubly fed induction generator," IEEE Trans. Energy Conversion, vol. 18(2), pp. 194-204, Jun 2003.

[12] Slotine, J.J.E. Li, W, "Applied nonlinear control," Prence Hall, USA, 1998

[13] L. M. Fernandez, C. A. Garcia, F. Jurado,"Comparative study on the performance of control systems for doubly fed induction generator (DFIG) wind turbines operating with power regulation," Journal of Elsevier of Energy, vol.33(09), pp.1438-1452, Sep 2008.

[14] X. Yao, C. Yi, D. Ying, J. Guo and L. Yang, "The grid-side PWM converter of the wind power generation system based on fuzzy sliding mode control," Advanced Intelligent Mechatronics, IEEE 2008, Xian (Chine).

[15] M. Loucif, "Synthèse de lois de commande non-linéaires pour le contrôle d"une machine asynchrone à double alimentation dédiée à un système aérogénérateur," Thèse de Doctorat de l"Université Aboubakr Belkaïd-Tlemcen, 2016.

[16] Y. Bekakra, "contribution à leetude et à la commande robuste d"un aérogénérateur asynchrone à double alimentation, "Thèse de Doctorat de l"Université Mohamed Khider-Biskra, 2014

[17] H. Hashimoto, H. Yamamoto, D. Yanagisawa, F. Harachima, "Brushless servomotor control using VSS approach," IEEE TAS Annuel Meeting, pp. 72-79, 1986.

[18] B. Bossoufi, M. Karim, A. Lagrioui, M. Taoussi, A. Derouich "Adaptive backstepping control of DFIG generators for wide- range variable-speed wind turbines system," Journal of Electrical Systems JES, vol.10(3), pp. 317-330, Sep 2014.

[19] Fillipov, A. F. "Differential equations with discontinuous right-hand side," Amer.Math.sco.Trans, vol. 62, pp. 199231,1960

[20] Utkin, V. I., "Sliding modes and their application in variable structure systems," Mir, Moscou, 1978.

[21] N, HAMDI, "Amélioration des performances des aérogénérateurs," Thèse de Doctorat de l"UNIVERSITE CONSTANTINE I, 2013

[22] Y. Bekakra, D. Ben Attous, "Sliding mode controls of active and reactive power of a DFIG with MPPT for variable speed wind energy conversion," Australian journal of basic and applied sciences, vol 5(12), pp. 2274-2286, 2011.

[23] Hamerlain, M., "Commande hiérarchisée à modèle de référence et à structure variable d"un robot manipulateur à muscles artificiels," Thèse de Doctorat INSA, Toulouse, 1993

[24] Floquet, T., "Contributions à la commande par modes glissants d'ordre supérieur," Thèse de doctorat, Université des Sciences et Technologies de Lille, 2000. 